\title{
SOBRE A IMPORTÂNCIA DO SISTEMA DE AVALIAÇÃO DE PROFESSORES: UMA ENTREVISTA COM CHARLOTTE DANIELSON
}

Luís Roberto de Souza Júnior

A consultora educacional americana Charlotte Danielson é uma das mais reputadas especialistas em avaliação docente dos Estados Unidos. Como formação em algumas das principais universidades estadunidenses e inglesas (Cornell, Oxford e Rutgers) em História, Filosofia e Administração e Supervisão Educacional, Danielson escreveu vários livros sobre planejamento curricular, prática docente e avaliação de professores. Em seu livro mais conhecido, Melhorar a prática profissional: um quadro de referência para a docência (em tradução portuguesa editada pelo Ministério da Educação de Portugal), ela formulou um modelo - intitulado The Framework of Teaching - que serve tanto para guiar o trabalho dos professores quanto para avaliá-lo. O modelo tem sido aplicado com sucesso em seis estados estadunidenses e em países como Chile e Portugal.

O The Framework of Teaching prega que os critérios da avaliação devem ser elaborados a partir de um consenso sobre a melhor forma de ensinar. Danielson propõe o que seria essa "melhor forma de ensinar" com base em estudos empíricos e pesquisas teóricas que ela identificou como responsáveis por melhorar o aprendizado do aluno. No The Framework of Teaching, a atividade docente é dividida em 22 componentes, que são separados em quatro áreas principais: planejamento e preparação; ambiente em sala de aula; ensino e responsabilidade profissional.

$\mathrm{Na}$ entrevista a seguir, Danielson afirma que a avaliação de professores não deveria ser um assunto polêmico, pois "um bom sistema de avaliação de professores garante a qualidade do ensino e o crescimento profissional dos professores". Defende o diálogo entre professores e avaliadores e ressalta a importância de professores que saibam reconhecer os próprios pontos fracos e de avaliadores que façam julgamentos baseados em evidências.

A senhora tem várias obras publicadas e é uma das mais respeitadas especialistas em qualidade e avaliação docente, mas sua formação acadêmica, apesar de ter sido em universidades renomadas, não foi inicialmente direcionada para a área.

CD: Ao longo de minha carreira, dei aulas para quase todos os níveis escolares, desde o jardim da infância até a faculdade. Também fui diretora, coordenadora curricular e responsável pelo treinamento de professores e usei essa experiência para elaborar o The Framework of Teaching. Mas a princípio estudei História (ele se graduou na Universidade de Cornell, com especialização em História Chinesa). Depois fui para Oxford, onde fiz mestrado em Filosofia, Política e Economia. Duas décadas depois, em 1978, quando eu já lecionava e tinha interesses nas áreas de planeamento 
curricular, avaliação de desempenho e desenvolvimento profissional de professores, cursei um outro mestrado, desta vez na Universidade de Rutgers, em Administração e Supervisão Educacional.

A avaliação de professores é uma questão polêmica. Por que nem todos os professores aceitam essa prática?

CD: Esse não deveria ser um assunto polêmico. Os professores precisam entender que foram contratados para fazer um trabalho importante, mas, como em qualquer outro trabalho, o empregador precisa saber se o funcionário está se saindo bem em sua função. Um bom sistema de avaliação de professores garante a qualidade do ensino e o crescimento profissional dos professores.

Infelizmente, o cenário não é bom na maioria dos lugares. A maior parte dos sistemas de avaliação não é levada a sério nem pelos professores nem pelos administradores. São sistemas construídos com base em critérios defasados e com avaliadores mal treinados para exercer sua função. É necessário que um sistema seja capaz de diferenciar os professores excelentes de verdade dos que são meramente competentes, e o sistema deve fazer isso de uma maneira considerada válida e justa por todos.

A questão que deveria ser colocada não é se o desempenho do professor deveria ser avaliado, mas como fazer essa avaliação. Claro, é essencial que o desempenho dos professores seja avaliado por pessoas capacitadas para isso. Os critérios da avaliação devem ser elaborados a partir de um consenso sobre qual seria a melhor forma de ensinar. A avaliação existe para promover reflexão e estimular o crescimento profissional. A ideia é que os professores evoluam com ela.

\section{Como o professor pode se autoavaliar?}

CD: A autoavaliação é um ótimo instrumento de crescimento profissional, mas só funciona se os professores forem sinceros ao fazê-la. Para que isso aconteça, a autoavaliação não deve ser submetida aos superiores ou compartilhada com os colegas. Trata-se de um assunto privado. Porém, se há um bom ambiente de trabalho, os resultados da autoavaliação pode servir de alavanca para uma troca de ideias envolvendo os professores e diretores sobre o que precisa ser melhorado.

No seu livro Melhorar a prática profissional: um quadro de referência para a docência, são citados quatro parâmetros para guiar o trabalho de um professor:

- planejamento e preparação

- ambiente em sala de aula

- ensino

- responsabilidade profissional.

Como funciona a avaliação docente dentro de cada um deles? 
CD: O modelo pressupõe que a complexidade da atividade de ensinar é amplamente reconhecida e estende-se a vários aspectos do trabalho docente. $\mathrm{O}$ ambiente em sala de aula e o ensino são avaliados por um observador durante as aulas. Já o planejamento e a preparação e a responsabilidade profissional às vezes não aparecem muito no dia-a-dia em sala de aula, a não ser indiretamente, e para avaliar estes itens são necessários outros procedimentos, como entrevistas com o professor. Por exemplo, um componente importante para a responsabilidade profissional é a comunicação do professor com as famílias dos alunos. Então o avaliador deve pedir ao professor que explique como essa comunicação ocorre. Aqui cabe outra vez ressaltar que essas entrevistas do avaliador com o professor podem ser muito interessante e extremamente recompensadoras, transformando-se numa troca de ideias para melhorar o nível das aulas. E claro que isso é uma visão simplificada do sistema, porque o Framework of Teaching é bem detalhado, dividido em itens e subitens.

\section{O que deve ter um bom sistema de avaliação de professores?}

CD: Como explico em meus livros, inicialmente em Melhorar a prática profissional: um quadro de referência para a docência e depois em Teacher Evaluation to Enhance Professional Practice (escrito em parceria com Tom McGreal), podemos pensar em um bom sistema de avaliação de professores composto por três itens principais: uma definição clara do que é ensinar bem; métodos de avaliação justos e confiáveis no momento de identificar as evidências de que o ensinar bem está sendo praticado; e avaliadores bem treinados que podem fazer julgamentos baseados nessas evidências.

Poderia esses itens? Por exemplo, a senhora afirma que o primeiro passo para avaliar um professor é deixar claro, tanto para o avaliador quanto para os que serão avaliados, o que é “ensinar bem”. O que seria uma definição coerente de "ensinar bem"?

CD: Quando se vai avaliar alguma coisa, não importa o quê, é necessário haver um parâmetro de excelência. Todas as outras partes do sistema de avaliação dependem do claro entendimento desse parâmetro. Tomemos alguns exemplos: para conceder uma carteira de motorista ou para deixar que candidatos se formem em medicina ou entrem na Ordem dos Advogados. Antes de tudo é necessário estabelecer o que constitui um exercício aceitável da profissão. Todas as outras partes de um sistema de avaliação dependem disso.

Falando de um modo geral, em minha modesta opinião, a melhor definição de ensinar bem é o que consta em meus livros. É um ensino alicerçado em muita pesquisa dos professores e planejamento curricular, e ainda é adaptável para todas as teorias educacionais. Eu também acho 
que se uma escola estiver usando uma metodologia muito específica, o que, aliás, não sei se é uma boa ideia, essa metodologia deve estar contida nessa definição de ensinar bem.

Usando uma linguagem mais comum, deveríamos perguntar "O que os bons professores fazem em sala de aula? E até que ponto isso varia de acordo com o contexto (por exemplo, numa aula do ensino fundamental e numa aula de biologia no ensino médio)?” Não deveria haver controvérsia sobre isso.

\section{A noção de "ensinar bem" muda conforme o projeto da escola?}

CD: De um modo mais particular, o conceito de ensinar bem pode sofrer ajustes de acordo com as particularidades em cada faixa etária escolar. Alguns critérios de avaliação podem ser mais importantes para o professor do Ensino Fundamental do que para o professor do Ensino Médio, e vice-versa. Por isso sugiro que uma comissão de educadores seja formada para estabelecer a importância de cada critério da avaliação.

No meu livro em Melhorar a prática profissional: um quadro de referência para a docência e depois em Teacher Evaluation to Enhance Professional Practice, há um exemplo do que do que poderia ser uma estrutura que descreve o que se espera de um professor (Ver anexo enviado pela entrevistada).

\section{E como definir métodos de avaliação justos e confiáveis para identificar que o "ensinar bem" está sendo praticado?}

CD: Devemos pensar aqui em procedimentos gerais de avaliação (que podem variar de acordo com o tempo de carreira do professor avaliado), o tempo necessário para levar a cabo a avaliação, o pessoal envolvido, as formas específicas e os critérios usados. Tudo isso deve estar claro para todos os que participam do processo e tudo isso deve servir de norma a todos. Por exemplo, haverá observações na sala de aula? E se houver, quantos avaliadores estarão presentes? Os professores serão informados previamente de que os avaliadores estarão presentes? Os professores experientes serão avaliados da mesma forma que os novatos? O desempenho dos estudantes será levado em conta na avaliação do professor? Planos de aula pedidos aos professores ou avaliação será com base na aula? O que mais será pedido aos professores?

Os professores podem assumir um papel ativo num sistema que os avalia. Quando isso ocorre, quando se pede, por exemplo, aos professores para escrever um relatório sobre o sucesso de uma matéria ensinada, quando se pede aos professores para analisar constantemente o envolvimento dos alunos com a escola, a tendência é que os professores obtenham resultados melhores. Esses relatórios podem servir de instrumentos adequados a autorreflexão dos professores, porque a decisão de inclusão de evidências em detrimento de outras implica sempre uma escolha precedida 
de reflexão e avaliação, possibilitando o desenvolvimento de um processo de aprendizagem na e sobre a profissão docente. Se o sistema de avaliação englobar métodos que permitam aos professores participarem ativamente, isso leva a um diálogo em geral recompensador.

E avaliadores qualificados? Como deve ser a preparação dos profissionais que vão avaliar o trabalho do professor?

CD: Avaliadores qualificados quer dizer que eles estão preparados para fazer julgamentos baseados em evidências. Do ponto de vista dos professores, não deveria importar quem é o responsável pela avaliação, pois o resultado deveria ser o mesmo. Essa consistência do julgamento dos avaliadores é que garante a confiabilidades do sistema como um todo.

O treinamento dos avaliadores é uma das partes mais importantes, uma vez que assegura a justiça do processo de avaliação. Isso por sua vez faz com que os professores confiem no resultado da avaliação. Em geral, usando o The Framework of Teaching, o treinamento para observar e saber julgar o ambiente em sala de aula e o ensino dura três dias. Neste período, o avaliador estuda o método de avaliação e aprende a ser o mais objetivo possível, diferenciando fato de opinião.

Se a escola (ou país) quer formar avaliadores de planejamento e a preparação das aulas e a responsabilidade profissional do professor, então são necessários mais dois dias. O período de treinamento deve ser de dedicação exclusiva, com atividades extra classe como leitura de apostilas.

Como se dá a avaliação dos outros procedimentos citados em The Framework of Teaching: conferências, análise do trabalho do aluno e os recursos e materiais utilizados pelo professor?

CD: Os professores só podem ser avaliados com justiça em relação ao que controlam, ou seja, que nível de excelência conseguem alcançar ao ensinar seus alunos usando os recursos à disposição. Claro que algumas escolas possuem materiais melhores e estruturas mais completas do que outras. A partir daí, deve-se esperar que os estudantes das escolas com mais estrutura consigam resultados melhores. A avaliação dos professores não pode ser influenciada por isso. Eles não podem ser punidos porque a escola em que trabalham não oferece condições tão boas quanto as de outras escolas.

Deve haver sistemas diferentes de avaliação de professores de acordo com a experiência que eles têm ou com as dificuldades que enfrentam?

CD: O sistema não precisa ser diferente, mas a experiência em sala de aula ajuda muito. Por isso, é razoável esperar que um professor experiente tenha um desempenho melhor do que um novato. Da mesma maneira, é normal que professores que vivem situações de maior pressão tenham seu desempenho comprometido. Entretanto é importante que todas essas coisas não sejam usadas 
como desculpas para um desempenho fraco. A falta de experiência ou uma situação que exija mais do professor devem ser encaradas como um desafio, uma oportunidade para o professor melhorar sua habilidade de dar aula e lidar com alunos. Em minha opinião, essa deve ser a regra, mas claro que também existem problemas incontornáveis.

\section{Qual a frequência com que os professores devem ser avaliados?}

Levando em conta o que foi dito na resposta da questão anterior, os professores em início de carreira devem ser avaliados todos os anos. Já um professor com mais experiência e com bom histórico de desempenho pode ser avaliado a cada três anos.

A senhora também cita a importância da comunicação do professor com a família do aluno. Como deve ser essa relação e de que forma ela deve ser avaliada?

$\mathrm{CD}$ : Existem várias maneiras de os professores se comunicarem com a família do aluno, e é até desejável que se use mais de uma. Pode-se, por exemplo, enviar periodicamente boletins informativos sobre o comportamento do aluno em sala de aula, ou descrições do que está sendo ensinado, ou ainda instruções sobre uma viagem promovida pela escola. Também é recomendável ligar de vez em quando ou trocar e-mails.

Há duas formas de avaliar se a comunicação está ocorrendo efetivamente. Uma é pedir aos professores exemplos de contatos que eles fizeram com as famílias dos alunos. Outra é perguntar aos pais dos alunos se eles acham o professor acessível o suficiente. Essas duas maneiras são complementares.

Até que ponto a avaliação de desempenho dos alunos pode servir de parâmetro para a avaliação de desempenho dos professores?

CD: Esse é um grande debate nos Estados Unidos atualmente. Cada professor tem a obrigação, que faz parte da missão de ensinar, que é a de incentivar e ter um controle se os alunos estão se desenvolvendo, em termos de conhecimento, estratégias, comportamento e atitudes, da maneira e no momento esperados. Essa obrigação consta no The Framework of Teaching.

Uma vez dito isso, minha opinião é que o desempenho dos professores não pode ser avaliado pelo desempenho dos alunos em provas. Acho que isso deve fazer parte da troca de ideias entre o avaliador e o professor, mas não pode ser determinante para julgar a competência do professor. A principal razão para eu defender esse ponto de vista é que há muitos fatores que influenciam a aprendizagem do aluno, e os professores somente controlam alguns deles.

Em sua opinião, a formação de um professor nunca está completa. De que forma a organização da carreira do professor e a avaliação docente se relacionam ou deveriam se relacionar? 
CD: Em geral, eu acredito que lecionar é muito complexo, e por isso os professores nunca completam sua formação, mais experiência e conhecimento sempre ajudam.

Um sistema de avaliação docente bem estruturado pode contribuir para a carreira dos professores ao detectar em que aspectos eles devem melhorar. Mas isso só acontecerá se o professor estiver disposto a reconhecer seus próprios pontos fracos.

Em que países, estados ou cidades essas ideias defendidas pela senhora são aplicadas? Quais os resultados já obtidos? Qual a demora para que fossem implantadas? Houve resistência?

CD: O The Framework of Teaching foi adotado em seis estados norte-americanos, o que corresponde a milhares de escolas, não sei exatamente o número. A implantação plena do sistema normalmente leva alguns anos e deve ser muito bem planejada, uma vez que todos os professores têm de entender os critérios pelos quais serão avaliados e os avaliadores precisam receber treinamento.

A senhora sabe algo do sistema educacional brasileiro? Se sim, como vê o papel da avaliação docente para a melhoria da qualidade do ensino dentro desse cenário atual?

CD: Na América Latina, já trabalhei no Chile, adaptando para lá o The Framework of Teaching (o modelo de Charlotte foi a base para a elaboração para o "Marco para la buena enseñanza" [2003], elaborado pelo Ministério da Educação do Chile e outros órgãos, como a entidade que representa os docentes dos ensinos fundamental e médio do país), mas infelizmente não sei muito do sistema educacional brasileiro. No entanto, certamente vocês enfrentam vários desafios específicos da condição do país, e um sistema de avaliação deve sempre levar isso em conta.

De que forma pode ser realizada num país das dimensões dos Brasil, com redes imensas, uma avaliação que foque a observação da prática? Quem vai observar? Como isso poderia ser viável?

CD: Em geral, os professores deveriam ser avaliados por pessoas que podem observar o desempenho deles em sala de aula e também ver como é a convivência deles com os alunos, pais e colegas de profissão. Na maior parte dos casos, a pessoa que mais acompanha o dia a dia da escola e que por isso seria a mais indicada para avaliar os professores é o diretor ou o chefe de departamento. Porém essa pessoa deve ser treinada para assumir este papel. Assim fará julgamentos justos, sempre baseados em evidência.

Outra opção é preparar muito bem um grupo de avaliadores para que eles possam atuar em várias escolas, ficando um tempo em cada uma para observar os professores em ação. Essa me 
parece ser a melhor opção, garantindo avaliadores capacitados e avaliações mais objetivas, sem influência das preferências pessoais. Por outro, o custo é maior e os avaliadores externos não sabem detalhes da cultural de cada escola.

Recebido em: 08.01.2015 Aceito em: 4.10.2015 